\title{
DE ONDINAS, PINTORES, ESCRITORES Y CUENTISTAS
}

\author{
Leticia BRAVO BANDERAS
}

Colegio Nuestra Señora de la Victoria HH. Maristas (Málaga)

ulisestres@gmail.com

\section{Resumen}

Desde la Antigüedad más remota hasta nuestros días las ninfas de las aguas han protagonizado leyendas, historias y cuentos que nos hablan de la fascinación que los seres sobrenaturales ejercen sobre los humanos, así como de la imposibilidad del amor entre unos y otros. Las ondinas de manera significativa protagonizan una gran parte de estos relatos. También han sido inspiración para los pintores especialmente a partir del Romanticismo. Ondina, del joven pero ya consagrado Benjamin Lacombe, conjuga de manera magistral ambos elementos y muestra una vez más la vigencia de los motivos clásicos y del folklore tradicional.

Palabras clave: ondinas, Romanticismo, prerrafaelismo, tradición, creación, vanguardia.

\section{D'ONDINES, DE PEINTRES, D'ÉCRIVAINS ET DE CONTEURS}

\section{Résumé}

Depuis la plus lointaine Antiquité jusqu'à nos jours, les nymphes d' eau ont été les protagonistes de légendes, d' histoires et de contes qui nous racontent la fascination que les êtres surnaturels exercent sur les humains, ainsi que l'impossibilité de l'amour entre eux. Les ondines jouent un rôle important dans beaucoup de ces histoires. Elles ont également été une source d'inspiration pour les peintres, surtout depuis le romantisme. Ondina, du jeune mais déjà consacré Benjamin Lacombe, combine magistralement les deux éléments et montre une fois de plus la validité des motifs classiques et du folklore traditionnel. 
Mots-clés: ondines, littérature, Romantisme, préraphaélisme, tradition populaire, creation, avantgarde.

\title{
OF UNDINES, PAINTERS, WRITERS AND STORYTELLERS
}

\begin{abstract}
From the most remote Antiquity to our days, the nymphs of the waters have led legends, stories and tales that speak to us about the fascination that supernatural beings exercise on human beings, as well as of the impossibility of the love between them. The undines lead a great part of these tales. They have also been an inspiration for the painters especially from the Romanticism. Undine, from the young but already consecrated, Benjamin Lacombe, brings together in a magisterial way both elements and shows once again the force of classic motives and of traditional folklore.
\end{abstract}

Key words: undines, literature, Romanticism, Pre-Raphaelitism, tradition, creation, avant-garde.

«Estas cosas no ocurrieron jamás, pero son siempre»

Salustio, De los dioses y del mundo

La tormenta arrecia. El sintagma favorito de los meteorólogos en las últimas semanas es ciclogénesis explosiva. La recomendación general es permanecer en casa y no desplazarse por carretera salvo que sea por verdadera necesidad. Sin embargo, la vida no se detiene. Hace mucho frío y la lluvia cae con mucha fuerza, pero la mayoría tiene que acudir al trabajo, atender sus negocios, resolver asuntos, visitar al médico, llevar o recoger a los niños, hacer compras... Se acerca la Navidad. El brillo de las luces que la anuncian se confunde con el de los neones de la publicidad. Filtradas esas luces por las enormes gotas de lluvia que sin cesar caen desde el cielo, producen un efecto lumínico extraño que da apariencia de irrealidad o sueño a esta tarde cualquiera del invierno.

Para quien observa desde arriba la ciudad emerge sin descanso como una enorme marea humana entre la que sobresalen a distintas alturas los semáforos con sus constantes cambios de luz, los postes 
de la electricidad, las farolas o los árboles atrapados en sus pequeños alcorques. Alguien se cruza, otro camina deprisa, muchos hablan con otro a través del teléfono móvil, los coches pasan velozmente al borde de la acera, las madres cubren a los niños, un perro se protege, como puede, bajo el dintel de una puerta. La ciudad es un ir y venir incesante de personas y vehículos, destellos, sonidos, ruidos y silencios. El caminante se siente empujado por esa marea humana que, en una dirección y en la contraria, avanza, empuja o envuelve. El viento sopla cada vez con más fuerza como quien gime desde muy profundo.

El caminante entonces se detiene ante el cristal de un escaparate. El agua lo salpica con tal fuerza y se desliza por él con tanta violencia que no es fácil percibir lo que hay al otro lado. Poco a poco los ojos del caminante se acostumbran a mirar. A su alrededor se ha hecho el silencio. Ya no siente gemir el viento, ni todo parece tan oscuro o turbio. Durante un rato contempla maravillado y en silencio a la criatura que se asoma tras la limpia cortina de agua. La ondina, Ondina, no lo mira. Absorta, ensimismada, acaricia algunos mechones de su larguísima, preciosa y roja cabellera adornada de nenúfares. El caminante se lleva la mano a la cartera, cruza la puerta del establecimiento como quien se dirige a otro mundo y avanza directo hacia aquellos ojos claros, hacia aquellas mejillas sonrosadas, hacia aquellos labios jugosos. Contempla a la criatura en toda su belleza misteriosa y melancólica. Sostiene entre sus manos el preciado objeto, pasa por caja y sale feliz con su conquista, fortalecido y dispuesto de nuevo a enfrentarse a las sombras, mientras aguarda el momento de llegar a casa para entregarse a su deleite. La puerta de la librería se cierra sin estruendo. En sus oídos el caminante lleva la dulce melodía que sonaba entre los libros.

Es el año 2012 y en esta ocasión de la mano de Benjamin Lacombe ha vuelto a producirse el hechizo. Una vez más Ondina, una ondina, ha ejercido su seducción sobre un humano. 


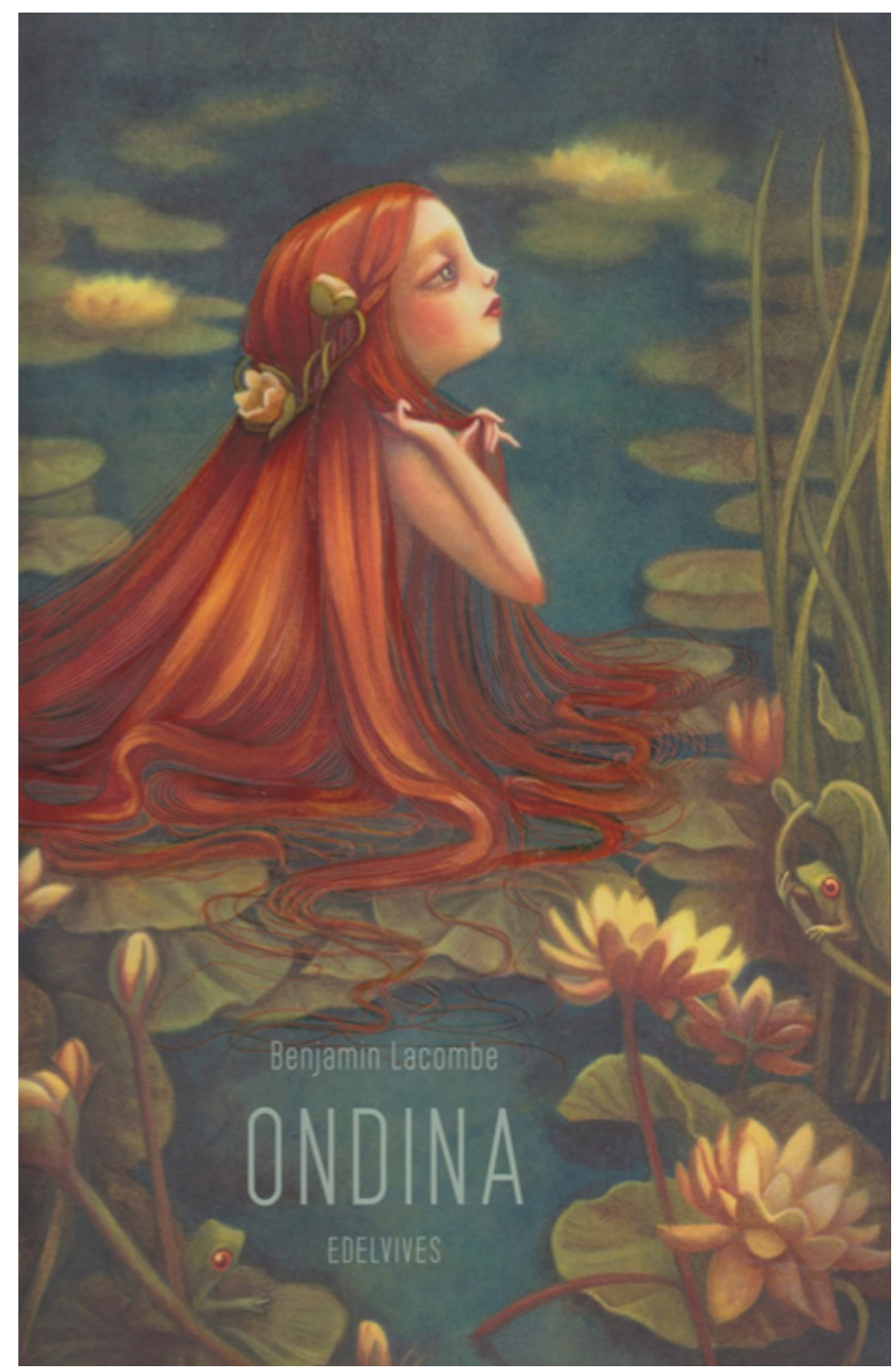

Imagen 1. Cubierta () 2012, Benjamin Lacombe. Ondina. Edición en castellano: Editorial Luis Vives.

La Ondina de Lacombe, como el propio autor afirma al final del libro, tiene como fuentes de inspiración, ya que hablamos de agua, dos torrentes: por una parte, la propia literatura; por otra, la pintura.

En lo literario esta Ondina es heredera, aunque en una adaptación muy libre, de la de Friedrich de La Motte-Fouqué, considerada por la crítica como la realización literaria más lograda de esta historia, y de la de Giraudoux. Resulta interesante destacar que existe una edición de la Undine de La Motte-Fouqué del año 1909 que fue ilustrada por el inglés Arthur Rackham, uno de los grandes de la ilustración de todos los tiempos.

En lo pictórico, Lacombe reconoce su deuda con Rossetti, Millais, Waterhouse y Hokusai, maestros 
a los que dedica este trabajo por la inspiración que han supuesto para él. Cualquiera familiarizado con la obra de estos pintores advierte en cuanto contempla la Ondina de Lacombe el homenaje que el ilustrador parisino ha materializado en sus páginas.

La creencia en la existencia de espíritus semidivinos, sobrenaturales, benefactores o maléficos, vinculados a la Naturaleza en estado virgen es tan antigua como el hombre. La comunicación y el contacto con estos espíritus se aceptaba siempre como un acontecimiento extraordinario y problemático pues se asumía que contaban con poderes mágicos, conocimientos específicos y capacidad para intervenir en la vida de los hombres en determinados momentos o interrumpir el curso normal de los acontecimientos. Es por ello que las mitologías de todos los pueblos que en el mundo han sido están pobladas en sus bosques, árboles, ríos, lagos, mares, etc. de infinidad de criaturas misteriosas que producen a un tiempo sobre los seres humanos miedo y atracción.

El agua, elemento indispensable para la vida del hombre, origen mismo de la vida y fuente de peligros, ha sido espacio privilegiado y fecundo para dar existencia a toda clase de criaturas. Así nacieron las sirenas, las náyades, las ninfas, las nereidas y las ondinas. Como afirma Elvira Luengo (2007, pp. 482-3): «En las mitologías de todo el mundo se encuentran leyendas de Ondinas adaptadas a cada espacio: el país de Gales, Escocia, Irlanda, Francia, Alemania, Suiza, Colombia, El Bierzo; todas ellas presentan variantes, pero mantienen el arquetipo del cuento». Pensemos, por ejemplo, en las famosas xanas o lavanderas asturianas, en la preciosa leyenda de Bécquer Los ojos verdes o en el interesantísimo relato de Gertrudis Gómez de Avellaneda, La ondina del lago azul, en el que la explicación racional no merma en absoluto la belleza ni la sugestión que produce lo narrado.

El alquimista suizo Paracelso (Liber Nymphis) fue el primero en hablar de las ondinas. Las define como seres intermedios entre lo humano y lo animal, espíritus elementales de la naturaleza como las ninfas de la tierra, las salamandras del fuego o las sílfides del aire. Las ondinas viven en el agua y, puesto que carecen de alma, están destinadas a convertirse algún día en espuma, a menos que las salve un hombre con su amor. Sin embargo, Paracelso da buena cuenta de lo ruinosas que son para los hombres las relaciones con las ondinas y como prueba cita el poema escrito por Egenolf von Stauffenberg en 1320 (Lao, 2007, p. 150).

De las ondinas se decía que eran criaturas enigmáticas y misteriosas, pero también muy alegres, traviesas y juguetonas, a las que les gustaba bailar. Su risa y sus cantos ejercen una poderosa atracción 
sobre quienes las escuchan hasta el punto de poder hacerles perder la voluntad. El cabello muy largo es el rasgo físico más llamativo y representa la fuente de su poder y sensualidad. En muchas ocasiones eran vistas peinándose en las orillas de los ríos, al borde de los estanques o las fuentes. Como carecen de alma, no tienen conciencia del daño que pueden llegar a hacer, pues a menudo la muerte que provocan a los pescadores o viajeros no es producto de una mala voluntad, sino consecuencia de un juego con el agua enormemente divertido para ellas, mortal para el humano.

Algunas están dispuestas por amor a abandonar las aguas y seguir a un hombre. La única condición para que esto sea posible es conseguir una unión duradera. Si son víctimas de la infidelidad, la traición a una promesa o el desprecio, vulnerables e indefensas ante la falta de amor, no pueden más que regresar a su mundo donde incluso pueden sufrir castigo, puesto que no deja de ser una anomalía o desafío a la ley natural desear una vida y un amor que no les corresponde. Devueltas a su condición natural están obligadas por las leyes que rigen su mundo a ejecutar la venganza debida. Esta no es otra que la muerte del amante infiel. Ondina y Melusina son ejemplos paradigmáticos de este motivo.

Con la llegada a Europa del Romanticismo todo este material que había formado parte de las creencias íntimas de la gente y se había transmitido a lo largo de los siglos de generación en generación a través de innumerables relatos, se convirtió en objeto de estudio filológico y reelaboración artística. De la mano de autores como los hermanos Grimm el cuento se recupera como género literario bajo la designación de cuento fantástico o maravilloso. Y así podemos afirmar que «el tema de la ninfa de las aguas que busca encarnarse en el ser humano es un topos del cuento maravilloso» (Luengo, 2007, p. 481). La ondina se convierte desde la óptica romántica en la representación o el sueño de la inocencia primitiva frente al mundo corrompido y desnaturalizado de lo urbano. Por eso también estas historias se sitúan temporalmente en una atmósfera medieval que los románticos identifican en términos ideales con un mundo de verdadera fe y valores. En la Ondina de La Motte-Fouqué se establece un contraste cautivador entre la alegría, la vitalidad, la calma y la seguridad de la naturaleza y la casa de los ancianos y la tristeza y oscuridad que emana del castillo al que pertenece el caballero.

«Neorrománticos»o «tardorrománticos» son los adjetivos que muchos especialistas utilizan para calificar a los pintores prerrafaelistas, que a partir de 1848 dieron nacimiento en Londres a uno de los movimientos artísticos más fascinantes y peculiares de la historia del arte. Su estética ha sido capaz de traspasar y trascender la geografía y el tiempo, de tal modo que se les reivindica actualmente como una 
auténtica y vigorosa vanguardia sin la que no habrían sido posibles corrientes como el Simbolismo, el Art Nouveau o el Art Decó, por citar solo algunas. De entre las muchas e interesantes aportaciones que el Prerrafaelismo nos ha dejado, destacaremos solo las tres más relevantes para el contenido de este trabajo por su estrecha vinculación con la Ondina de Benjamin Lacombe que comentamos:

1. Su compromiso con un arte que reflejara de la manera más veraz posible la naturaleza, por la que sentían un venerable respeto y que trataron de reproducir en un principio con precisión casi fotográfica.

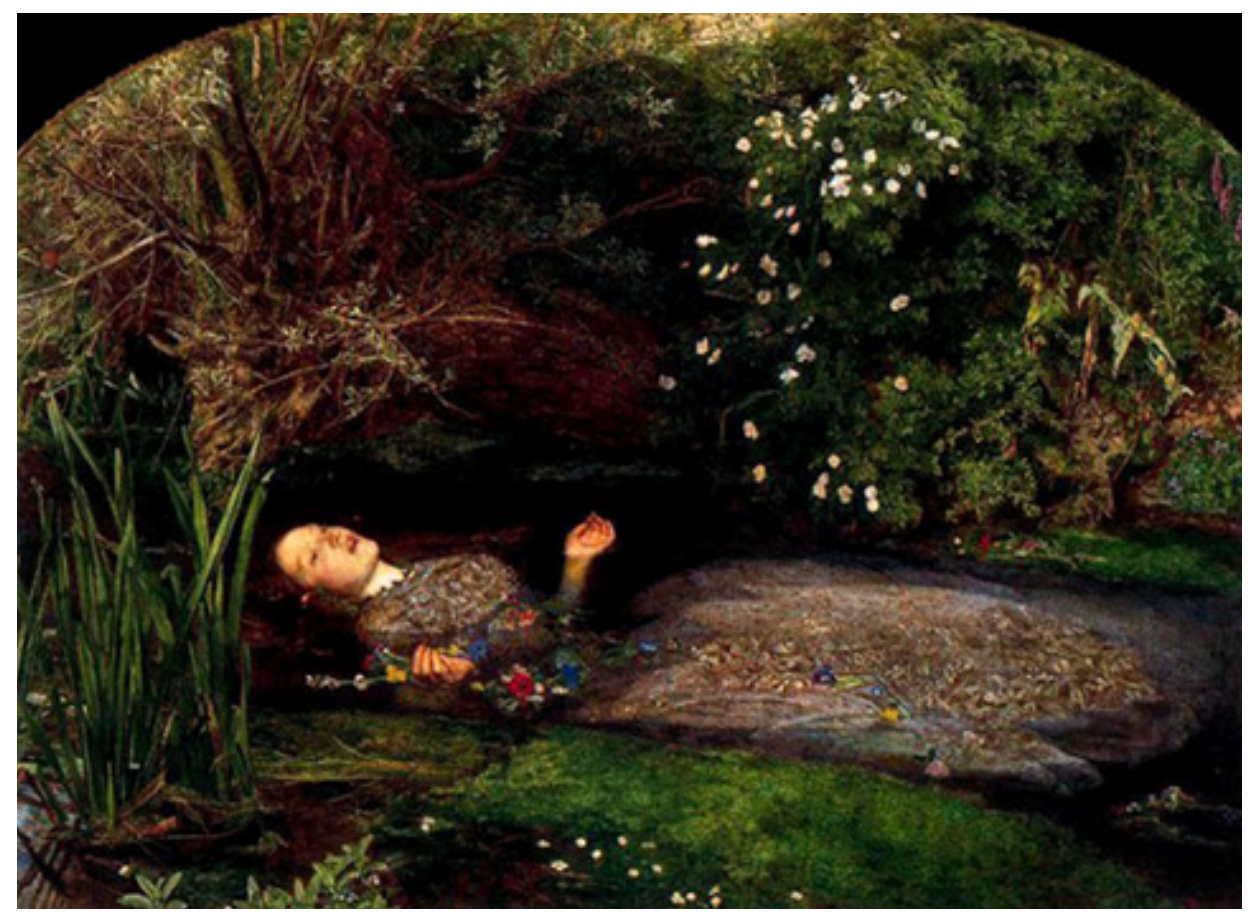

Imagen 2. John Everett Millais (1851-52). Ofelia. Tate Gallery, Londres. ${ }^{1}$

2. Su proyección vital y artística hacia un pasado medieval idealizado que les parecía el modelo de sociedad más humana y auténtica que el hombre había conocido y que utilizaban como arma artística para denunciar la fealdad e injusticia del mundo de la Revolución Industrial en el que les había tocado vivir.

3. Su tipología femenina, de éxito tan arrollador que continúa hoy siendo un prototipo de belleza. Mujeres de cabellera larga y abundante, negra o pelirroja; de largos, poderosos y estilizados cuellos; labios carnosos y sensuales; narices rectas; cejas grandes y pobladas; manos grandes y delicadas, con largos dedos; mujeres de figuras portentosas, altas y delgadas. Mujeres lejanas e inaccesibles, graves, misteriosas, siempre sensuales y distantes al mismo tiempo.

1 https://live.staticflickr.com/625/20666140091_ce58ed23d9_b.jpg 30/03/2021 
Estos rasgos, analiza Carlos A. Cuéllar (2006, pp. 73-76), dieron lugar a una tipología femenina que él propone reducir a un número de cinco: la doncella virginal e inofensiva de carácter religioso; la mujer andrógina semidivinizada; la mujer frágil y desvalida, típicamente romántica, necesitada de un héroe que la salve; la mujer perversa, de erotismo explícito y que acarrea la irremediable perdición del hombre; por último, la mujer-niña que, según el contexto, puede adaptarse a cualquiera de los grupos anteriores.

El pintor John William Waterhouse, para muchos un prerrafaelista tardío (no lo es en cuanto a la técnica pictórica, pero sí por el contenido de su obra) tomará el relevo junto a otros pintores en la recreación de estos motivos del Prerrafaelismo. Sus mujeres son, por lo general, más etéreas y delicadas que las de Rossetti, por ejemplo, pero ahí están las largas cabelleras rojas una y otra vez, así como una permanente atmósfera de ensoñación y misterio.

Contemplar la Ondina de Lacombe sumergida entre nenúfares y coronada por ellos nos conduce a otra laguna, aquella de Waterhouse en la que el joven Hylas está siendo irremediablemente arrastrado a las profundidades del agua por las ninfas con poderosa determinación. No podía ser presentada nuestra ninfa de otro modo, pues el nenúfar es el emblema del hielo, de la frialdad. Es también en muchas culturas (por ejemplo, en la egipcia) el símbolo del universo, de la unión del cielo con la tierra, de la vida y de la muerte, pues sus raíces se sujetan en el lodo del fondo, se alimentan y crecen entre aguas turbias, pero sus flores nacen en la superficie y se abren para contemplar los cielos.

En su reivindicación de un mundo renovado los prerrafaelistas proclamaron la necesidad de que la vida cotidiana de cada hombre se viera provista de objetos bellos. Entendieron la belleza como una condición indispensable para una vida más humana, acorde con las auténticas necesidades de un ser humano. Así nació el movimiento Arts and Crafts, liderado por William Morris. Entre sus muchas y diversas creaciones jugó un papel fundamental la edición de libros hermosos, cuidados hasta el más mínimo detalle. Estos libros nacidos de la Kelmscott Press son auténticas obras de arte, libros para leer, mirar y tocar en los que se manifiesta, como afirma Cuéllar, «la síntesis perfecta entre literatura y artes plásticas» (2006, p. 62).

En los últimos años, en gran medida impulsado desde países como Inglaterra, Francia, Italia y, felizmente, también España, se viene produciendo un auge de este modelo de edición preciosista, heredera en gran medida del empeño prerrafaelista por crear cosas bellas, en la que la imagen se valora 
y cuida tanto como el texto y se convierte en un instrumento imprescindible y valiosísimo para la comprensión y enriquecimiento del propio texto. Nos referimos a un género reciente e innovador en el que el código gráfico se combina con el código textual de diversas formas, se trata del libro-álbum. Por fortuna, en el ámbito de la literatura infantil y juvenil se publica un número enorme de álbumes de este tipo de una calidad asombrosa. Benjamin Lacombe ha dado muestras sobradas de ser un verdadero artista en esta forma de creación multimodal. Su Ondina es una buena muestra de ello.

Benjamin Lacombe (París, 1982) ha trabajado en el campo de la publicidad, la animación y el cómic. Además de ilustrar, escribe (como sucede en la obra que comentamos). La infancia, el rechazo social, lo gótico, la nostalgia, lo onírico, impregnado todo ello de referencias artísticas y literarias, son algunas de las constantes de su obra. Se sirve de técnicas diversas entre las que reconoce su predilección por el gouache y óleo sobre papel. El resultado de su trabajo son creaciones preciosistas, exigentes en el detalle, llenas de color, evocadoras e inclinadas a la melancolía, de modo que en una entrevista (Álvarez, 2013), con motivo de la exposición sobre su trabajo en el Museo ABC, reconocía que sus personajes esbozan sonrisas, pero nunca enseñan los dientes. Su estilo es muy característico y perfectamente reconocible. Su sello de identidad: los ojos. Ojos grandes, muy grandes y expresivos; con frecuencia tristes o sugerentes de una vida interior rica y compleja. Esos ojos enormes están insertos habitualmente en cuerpos pequeños, frágiles, cuyos rostros muestran una piel delicada, como de porcelana, y unos labios finos, pero de color intenso. Así es nuestra Ondina. 


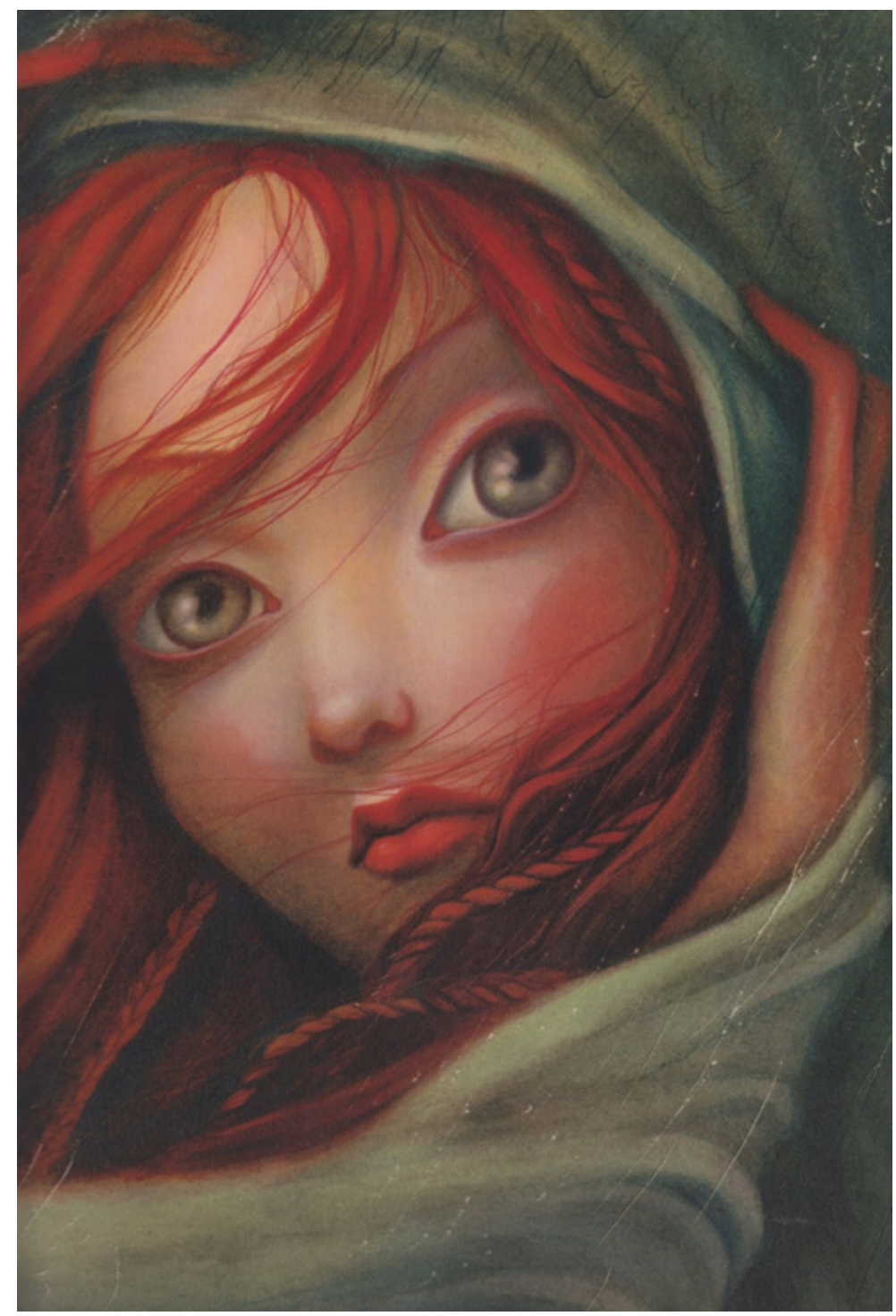

Imagen 3 (C) 2012, Benjamin Lacombe. Ondina. Edición en castellano: Editorial Luis Vives.

Todos estos rasgos que venimos comentando, heredados de la tradición del cuento popular y literario, del Romanticismo y de la pintura prerrafaelista, entre otros, creemos que están presentes en la Ondina de Lacombe con la fuerza, el cuidado y la belleza de quien sabe o entiende que la creación es también un juego de recreación constante.

Ondina narra la historia del caballero Herr Hans de Ringstetten que, tras perderse en un bosque encantando en mitad de una terrible tormenta, es encontrado por un viejo y humilde pescador que lo conduce a su casa. Allí al calor del modesto hogar y, acompañados por la anciana esposa del pescador, el caballero conoce a la bellísima hija adoptiva de estos. Su nombre es Ondina y el misterio que rodea su origen y su comportamiento es tan cautivador como su belleza. Tras un incidente peligroso 
y otros acontecimientos, el caballero decide permanecer con la peculiar familia a ese lado del bosque y así comienza una hermosa historia de amor entre él y Ondina que concluirá en boda. La noche nupcial Ondina le confiesa al caballero Hans cuál es su verdadera naturaleza y qué implica establecer un vínculo amoroso con alguien como ella. A pesar de su aspecto humano, Ondina es un espíritu acuático, una manifestación de las fuerzas de la naturaleza cuyo destino no es otro que disolverse en la nada, pero, si logra el amor verdadero de un hombre, entonces conseguirá un alma humana. Si en algún momento es traicionada en su amor, será devuelta a las profundidades a las que pertenece. Hans convence a Ondina de que su amor será capaz de superar cualquier dificultad que se les presente y en esa convicción vive feliz la pareja. Mientras su vida transcurre en los confines del bosque, al margen de la civilización, en la humilde casa de los ancianos en comunión con la naturaleza todo marcha de la mejor de las maneras. El amor sincero que ha otorgado a Ondina el alma que tanto deseaba ha operado en ella notables cambios. Atrás quedan los días en los que era imposible no quererla, pero también intentar comprender su peculiar conducta. Sin embargo, Ondina entiende que en algún momento su esposo debe volver al mundo al que pertenece. Así pues, se separan con dolor de los padres adoptivos de Ondina y emprenden el regreso al castillo de Ringstetten. En su nueva vida Ondina ha de aprender a manejarse en las intrigas de la corte. Para ello cuenta con la ayuda de Úrsula, la orgullosa hija adoptiva del duque, por cuyo desafío Hans se vio obligado a internarse en el misterioso bosque de la Selva Negra. Así llegó hasta Ondina y así dio comienzo esta historia. Ondina y Úrsula se hacen amigas y en su ingenuidad Ondina no ve nunca en ella la rival por el amor de Hans que realmente es. De este modo llegan la desconfianza, los celos y la traición. El amor de Hans no ha sido capaz de superar el abismo que separa su naturaleza humana, imperfecta y mortal, hecha para la vida en sociedad, de la de Ondina, elemental, ingenua, limpia y sin prejuicios. El desprecio y la ira de Hans condenan a Ondina a regresar a las aguas. Con el correr del tiempo una nueva boda se celebra. Es una boda muy distinta a aquella otra que un día feliz tuvo lugar entre el caballero Hans y Ondina. Los espíritus de las aguas empujan a Ondina a ejecutar la terrible venganza que toda ondina abandonada debe realizar. Las leyes de su mundo no admiten excepción. Ondina lucha consigo misma tratando de evitar la muerte de Hans. Ella sabe que ha sellado todas las entradas de agua del castillo y en este hecho cifra su esperanza. Pero Úrsula, desobedeciendo a la antigua señora del castillo ordena retirar la piedra que cubre el pozo. Entonces del pozo nace un diluvio que lo inunda todo a su paso y entre la espuma de sus olas se levanta 
la figura de una delicada novia velada. La silueta se dirige a Hans que la reconoce al instante. Con un último beso Ondina trae la muerte a quien tiempo atrás dio vida feliz. El castillo de Ringstetten y todo cuanto había en él queda sumergido bajo el agua.

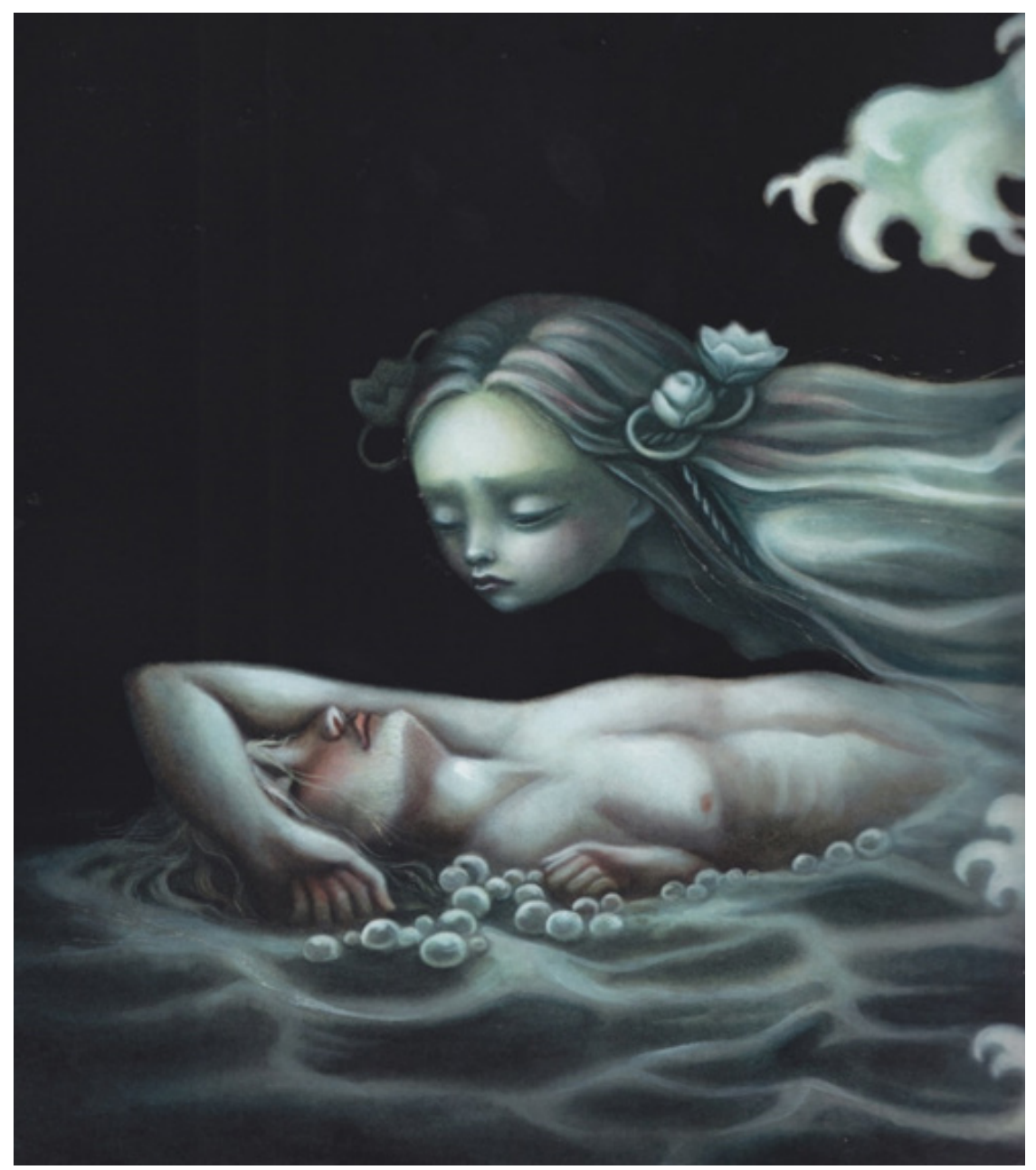

Imagen 4. (C) 2012, Benjamin Lacombe. Obra: Ondina. Edición en castellano: Editorial Luis Vives.

Para finalizar y, aunque resulte paradójico, regresamos al principio. El caminante llega a casa empapado. Se desprende de su ropa mojada. Comprueba que la calefacción ha cumplido su trabajo. Se da una ducha bien caliente. Experimenta con gozo cómo el agua devuelve la tibieza a sus miembros. Prepara una infusión de hierbas y toma asiento. Un día más ha sobrevivido a la ciudad y sus peligros. Un día más regresa a su hogar satisfecho por el deber cumplido. Coloca frente a sí el hermoso libro y lo abre con cuidado, respeto y amor, es decir, como hace todo buen lector. Afuera se oye incesante el correr del agua. Desde el fondo de la página ella dice: 


\section{Leticia Bravo Banderas}

[...] debes saber que soy un espíritu del agua, uno de esos personajes que aparecen en los cuentos y que tanto asustan a los niños. Nací sin conciencia y sin remordimientos. Desde que tengo memoria, deseo poseer un alma, y, según una antigua leyenda, si una criatura del agua llegara a conseguir el amor de un hombre, a cambio recibiría un alma humana. [...] Moriré de dolor si me dejas. (Lacombe, 2012, p. 16).

Y quién sabe... Es muy posible que esta vez el final de la historia resulte feliz. Nuevamente por efecto del amor, del amor a los libros bellos y a las buenas historias, Ondina, la juguetona, misteriosa y dulce ondina del lago, ha recibido el alma que esperaba.

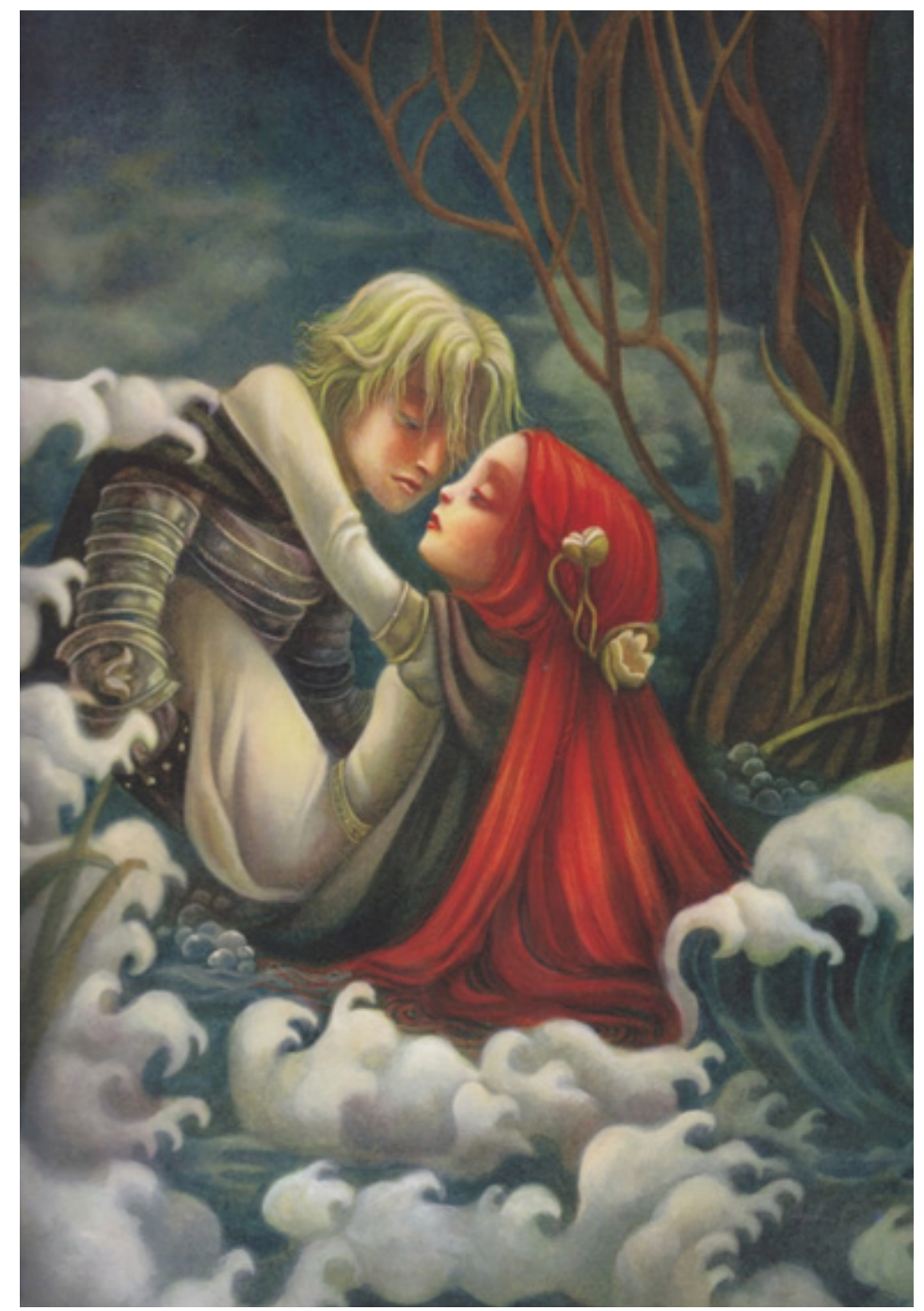

Imagen 5. (C2012, Benjamin Lacombe. Ondina. Edición en castellano: Editorial Luis Vives.

\section{Referencias bibliográficas}

AA.VV. (1989). Sobre la vida y poesía de Homero. El antro de las ninfas de la Odisea. Sobre los dioses 
y el mundo. Madrid: Biblioteca Clásica Gredos.

AA.VV. (2008). J. W. Waterhouse. The Modern Pre-Raphaelite. Londres: Royal Academy of Arts.

AA.VV. (2012). Beauté, Morale et Volupté dans l'Angleterre d'Oscar Wilde (Catalogues d'exposition). Milán: Skira Flammarion; París: Musée d'Orsay.

Bornay, E. (2010). Las hijas de Lilith. Madrid: Cátedra.

Cuéllar, C. A. (2006). El Prerrafaelismo y su influencia en la creación contemporánea. Valencia: Institució Alfons el Magnànim-Centre Valencià d'Estudis i d'Investigació.

Clutton-Brock, A. (2007). William Morris. Nueva York: Parkstone Press International.

Fouqué, F. de La M. [Friedrich de La Motte-Fouqué] (1987). Ondina. Ilustraciones: Arthur Rackham. Traducción: Carmen Bravo-Villasante. Barcelona: Hesperus.

García Gual, C. (2011). Metamorfosis de las sirenas, en L. Garagalza, (Ed.), Filosofía, Hermenéutica y Cultura: Homenaje a Andrés Ortiz-Oses (pp. 167-196). Bilbao: Publicaciones de la Universidad de Deusto.

Grimm, J. y Grimm W. (1985 y 1986). Cuentos de niños y del hogar. Volúmenes I y III. Traducción: María Antonia Seijo Castroviejo. Ilustraciones: varios. Madrid: Ediciones Generales Anaya. Herreros, A. C. (2010). Geografía mágica. Ilustraciones de Carlos Arrojo. Madrid: Siruela.

Hobson, A. (2001). J W Waterhouse. Londres: Phaidon Press Limited.

Lacombe, B. (2012). Ondina. Traducción: Elena Gallo Krahe. Zaragoza: Edelvives.

Lao, M. (2007). Seduction and the secret power of women. The lure of Sirens and Mermaids. Rochester, Vermont: Park Street Press.

Luengo Gascón, E. (2007). La frontera entre (dos) mundos: Ondina, en Pedro César Cerrillo Torremocha, Cristina Cañamares Torrijos y C. Sánchez Ortiz, (Eds.) Actas del V Seminario Internacional de «Lectura y Patrimonio» (pp. 481- 486). Cuenca: Ediciones de la Universidad de Castilla y La Mancha.

Metken, G. (1982). Los prerrafaelistas: el realismo ético y una torre de marfil en el siglo XIX. Traducción: José Luis Díaz de Liaño. Barcelona: Editorial Blume.

Reyero, C. (1992). El arte del siglo XIX. Madrid: Anaya.

Trippi, P. (2010). J. W. Waterhouse. Londres: Phaidon Press Limited.

Wilde, O. (1979). Cuentos. Ilustraciones: María Pascual. Barcelona: Ediciones Toray. 


\section{Documentos electrónicos}

Álvarez, Y. (2013). Benjamin Lacombe: «Por supuesto que dibujo sonrisas». hoyesarte.com (19 de diciembre 2013). URL: https://www.hoyesarte.com/entrevistas/c32-artistas/benjaminlacombe_147600/ 